\title{
Patients' Perceptions of Interpersonal Continuity of Care
}

Nancy Pandhi, MD, and John W. Saultz, MD

Purpose: The health system shift from doctor-patient continuity of care to team-based continuity may not match patients' preferences. This article reviews the existing medical literature regarding patients' perceptions of interpersonal continuity of care to determine which patients value interpersonal continuity and in what context.

Methods: A search of the ISI Web of Knowledge database from 1970 to April 2005 and the MEDLINE database from 1966 through April 2005 was performed to find articles that elicited patients' preferences or value for continuity of care. Thirty six articles were used for this synthesis.

Results: Interpersonal continuity of care is important to a majority of patients, particularly those from vulnerable groups. Patients value the relationship with their physician, their physician's knowledge about them, and the ability to communicate their concerns. Over time, contact with a physician seems to lead to the development of trust and confidence. However, continuity of care is not valued by all patients or across all settings.

Conclusions: Future research should continue to explore the importance of interpersonal continuity to patients. In particular, are there medical consequences when those whom desire continuity do not receive it? Clinicians should consider incorporating patients' preference for continuity into their office scheduling procedures. (J Am Board Fam Med 2006;19:390-7.)

The topic of continuity of care has enjoyed a recent resurgence of interest as societal and health system pressures encourage movement away from single physician-patient relationships to group model practices and team care. Over half of the articles indexed in Medline because 1966 under the topic heading continuity of patient care were published in the last 10 years. Several studies have pointed out the likely benefits of continuity of care including: improved receipt of preventive services ${ }^{1}$ and reduced hospitalizations ${ }^{2}$ and emergency department visits. ${ }^{3,4}$ Although continuity of care is considered a fundamental principle of primary care, little is known about patients' perceptions of continuity of care $^{5-8}$ and the extent to which the shift from physician continuity matches patients' preferences. Although, theoretically, United States' patients have access to different kinds of practices and con-

Submitted 3 August 2005; revised 3 February 2006; accepted 9 February 2006.

From the Department of Family Medicine, University of Wisconsin-Madison (NP); and the Department of Family Medicine, School of Medicine, Oregon Health and Science University (JS), Portland, OR.

Conflict of interest: none declared.

Corresponding author: Nancy Pandhi, MD, Department of Family Medicine, University of Wisconsin-Madison, 777 S. Mills Street, Madison, WI 53715 (E-mail: pandhi@wisc.edu). tinuity structures, groups such as uninsured and vulnerable patients often have less choice about the care they receive. Determining which patients value continuity and in what context is an important step toward examining the full impact of the shift away from doctor-patient continuity.

Multiple definitions and constructs for continuity of care exist. Continuity of care has been organized into a hierarchy ranging from basic information transfer (informational continuity) to an ongoing personal doctor-patient relationship characterized by loyalty, trust, and responsibility (interpersonal continuity). ${ }^{9}$ A previous systematic review concluded that interpersonal continuity is positively associated with patient satisfaction. ${ }^{10} \mathrm{Al}$ though patient satisfaction with interpersonal continuity is an important outcome, much remains to be explored regarding its context.

This review is a synthesis of the existing literature regarding patients' perceptions of an ongoing physician-patient relationship and interpersonal continuity. In particular, we examine the literature for answers to the following contextual questions: In what settings and for what conditions do patients value interpersonal continuity? Which patients value interpersonal continuity and why do they do so? Gaps in our current understanding of this area 
then are suggested as topics for future investigation. Practical applications of the information gained from this review toward clinical practice are also suggested.

\section{Methods}

The first and second author independently searched the literature using the search term "continuity of care." The ISI Web of Knowledge, a multidisciplinary citation database of over 8000 journals that allows a cited reference search from each article, and the Medline database were used to identify relevant articles published before April 2005. From this search, the 36 articles that directly elicited patients' preferences or value for continuity were retained and utilized for this synthesis.

These articles were reviewed by the primary author specifically to address contextual questions about interpersonal continuity. Results from the articles that provide answers to the contextual questions are reported if they were listed as statistically significant findings for articles that used quantitative methodology. For articles that used qualitative methodology, results are reported as they were stated in the article. Table 1 lists each contextual question asked and a brief description of the setting and methodology of each study used for this review.

\section{Results}

The studies utilized quantitative (19/36), qualitative $(16 / 36)$, or mixed methods (1/36). The largest number of the studies $(15 / 36)$ took place in the United States. Several took place in the United Kingdom (8/36), The Netherlands (4/36), and Canada (4/36). The remainder took place in other European countries (2/36), Australia (2/36) or both the United States and England (1/36). All recruited patients from ambulatory settings. A summary of results from these studies regarding our contextual questions is reported below.

\section{In What Settings Is Interpersonal Continuity of Care Valued?}

Across practice settings, studies have found that a majority of patients interviewed value interpersonal continuity. ${ }^{11,12}$ One study of patients at eastern United States academic medical center faculty practices found that nearly two thirds of patients preferred having one doctor take care of them. ${ }^{11}$ Another study of HMO patients from New En- gland reported that over $90 \%$ of respondents thought it was important or very important to have the same primary care physician take care of them over time. ${ }^{12}$

Few studies have looked at practice characteristics and patients' preference for site continuity versus interpersonal continuity. A qualitative study using focus groups of patients from the Montreal area found that a majority of patients preferred their own physician instead of a clinic as a usual source of care. ${ }^{13}$ In Britain, some practices operate partial personal list systems, where patients are assigned to a group of providers rather than one provider, similar to the structure of many United States group practices. One study found that patients in such practices were less satisfied with professional care and the depth of the doctor-patient relationship than those in practices that provided interpersonal continuity. ${ }^{14}$

Other literature suggests that patients may selfselect to practices according to what characteristics are important to them in terms of continuity and access. A survey of patients from combined and personal list practices found that patients from the personal list practices had much higher continuity scores and were more likely to prefer seeing a particular physician. ${ }^{15} \mathrm{~A}$ comparison of patients attending walk-in centers (similar to urgent care facilities) with those attending nearby general practices for same day appointments found that seeing the same doctor or nurse was preferred less by those at the walk-in center. Instead, the patients at walk-in centers preferred factors that assured ease of access such as convenient hours and shorter wait times. ${ }^{16}$ Likewise, Swiss outpatient residency clinic patients preferred convenience and rapid access to care, whereas private practice patients mentioned a preference for their physician's communication and technical skills. ${ }^{17}$ In contrast, another study found that preference for personal continuity did not seem to depend on physician-patient communication style. Patients of physicians whose styles rated poorer on communication equally preferred to see a usual physician as those with physicians with more highly rated communication styles. ${ }^{18}$

\section{Who Values Continuity?}

\section{Particular Groups}

Continuity seems to be more valued by certain groups of people. In particular, seniors, ${ }^{19,20}$ parents of the very young, ${ }^{20}$ those with Medicare and Med- 
Table 1. Questions Addressed in Patient Perceptions' of Continuity of Care Literature

\begin{tabular}{|c|c|c|c|c|c|c|}
\hline \multirow[b]{2}{*}{ Research Questions } & \multirow{2}{*}{$\begin{array}{l}\text { No. of } \\
\text { Studies } \\
\text { Addressing } \\
\text { Question }\end{array}$} & \multicolumn{5}{|c|}{ Reference Citations } \\
\hline & & Author & Year & Methodology & $\begin{array}{l}\text { No. of Research } \\
\text { Subjects }\end{array}$ & Location \\
\hline \multirow{8}{*}{$\begin{array}{l}\text { In what settings is } \\
\text { interpersonal } \\
\text { continuity of care } \\
\text { valued? }\end{array}$} & \multirow[t]{8}{*}{8} & Lewis et al. & 2000 & Quantitative & 314 & Eastern US \\
\hline & & Pereira et al. & 2003 & Quantitative & 1171 & New England \\
\hline & & Roberge et al. & 2001 & Qualitative & 23 & Montreal \\
\hline & & Baker & 1996 & Quantitative & 7273 & Britain \\
\hline & & Roland et al. & 1986 & Quantitative & 50 & Britain \\
\hline & & Salisbury et al. & 2002 & Quantitative & 6229 & Britain \\
\hline & & Perron et al. & 2004 & Qualitative & 26 & Switzerland \\
\hline & & Flocke et al. & 2002 & Quantitative & 2881 & Ohio \\
\hline \multirow[t]{12}{*}{ Who values continuity? } & \multirow[t]{12}{*}{12} & Schers et al. & 2002 & Quantitative & 644 & The Netherlands \\
\hline & & Pereira et al. & 2003 & Quantitative & 1171 & New England \\
\hline & & Brown et al. & 1997 & Qualitative & 29 & Canada \\
\hline & & Nutting et al. & 2003 & Quantitative & 3283 & Ohio \\
\hline & & Tarrant et al. & 2003 & Qualitative & 40 & England \\
\hline & & Kearley et al. & 2001 & Quantitative & 996 & England \\
\hline & & Mainous et al. & 2004 & Quantitative & 4454 & Ohio \\
\hline & & Mainous et al. & 2001 & Quantitative & 1068 & UK/US \\
\hline & & Brown et al. & 1997 & Qualitative & 42 & Canada \\
\hline & & Canady et al. & 1997 & Quantitative & 101 & Iowa \\
\hline & & Freeman et al. & 1993 & Quantitative & 111 & England \\
\hline & & Love et al. & 1999 & Quantitative & 466 & Kentucky \\
\hline \multirow{19}{*}{$\begin{array}{l}\text { For what medical } \\
\text { situations is } \\
\text { interpersonal } \\
\text { continuity of care } \\
\text { valued? }\end{array}$} & \multirow[t]{19}{*}{19} & Bjorkman et al. & 1995 & Qualitative & 94 & Sweden \\
\hline & & Nair et al. & 2005 & Qualitative & 46 & Ontario \\
\hline & & Schers et al. & 2002 & Quantitative & 644 & The Netherlands \\
\hline & & Lewis et al. & 2000 & Quantitative & 314 & Eastern US \\
\hline & & Pereira et al. & 2003 & Quantitative & 1171 & New England \\
\hline & & Nutting et al. & 2003 & Quantitative & 3283 & Ohio \\
\hline & & Tarrant et al. & 2003 & Qualitative & 40 & England \\
\hline & & Kearley et al. & 2001 & Quantitative & 996 & England \\
\hline & & Canady et al. & 1997 & Quantitative & 101 & Iowa \\
\hline & & Freeman et al. & 1993 & Quantitative & 111 & England \\
\hline & & Love et al. & 1999 & Quantitative & 466 & Kentucky \\
\hline & & Kibbe et al. & 1993 & Quantitative & 229 & North Carolina \\
\hline & & Temmink et al. & 2000 & Quantitative & 128 & The Netherlands \\
\hline & & Stoddart et al. & 2003 & Quantitative & 724 & England \\
\hline & & Infante et al. & 2004 & Qualitative & 76 & Australia \\
\hline & & Ware et al. & 2004 & Qualitative & 51 & Massachusetts \\
\hline & & Ware et al. & 1999 & Qualitative & 16 & Boston, MA \\
\hline & & Schers et al. & 2004 & Mixed & 875 & The Netherlands \\
\hline & & Christakis et al. & 2004 & Quantitative & 759 & Seattle, WA \\
\hline \multirow{16}{*}{$\begin{array}{l}\text { Why is interpersonal } \\
\text { continuity valued? }\end{array}$} & \multirow[t]{16}{*}{16} & Gabel et al. & 1993 & Qualitative & 60 & Ohio \\
\hline & & Nair et al. & 2005 & Qualitative & 46 & Ontario \\
\hline & & Schers et al. & 2002 & Quantitative & 644 & The Netherlands \\
\hline & & Roberge et al. & 2001 & Qualitative & 23 & Montreal \\
\hline & & Perron et al. & 2004 & Qualitative & 26 & Switzerland \\
\hline & & Brown et al. & 1997 & Qualitative & 29 & Canada \\
\hline & & Tarrant et al. & 2003 & Qualitative & 40 & England \\
\hline & & Mainous et al. & 2001 & Quantitative & 1068 & UK/US \\
\hline & & Brown et al. & 1997 & Qualitative & 42 & Canada \\
\hline & & Infante et al. & 2004 & Qualitative & 76 & Australia \\
\hline & & Lings et al. & 2003 & Qualitative & 34 & New York \\
\hline & & Liaw et al. & 1992 & Qualitative & 93 & Australia \\
\hline & & Pooley et al. & 2001 & Qualitative & 47 & England \\
\hline & & O' Malley et al. & 2000 & Qualitative & 24 & Washington DC \\
\hline & & Schers et al. & 2005 & Quantitative & 2152 & The Netherlands \\
\hline & & Torke et al. & 2004 & Qualitative & 26 & Atlanta, GA \\
\hline
\end{tabular}

icaid, ${ }^{20}$ those seen at least twice in the past 2 years for chronic conditions ${ }^{12}$ or requiring more medications, ${ }^{20}$ females, ${ }^{12}$ and the less educated ${ }^{20}$ give more importance to continuity of care. Continuity seems to be more important to nonwhite patients in one study ${ }^{12}$ but not in another. ${ }^{19}$ Thus, it is unclear from these studies if race alone leads to a continuity preference or if race is a proxy for another marker 
of disadvantage such as socioeconomic status. Interpersonal continuity seems to be less important to those who see themselves as busy or characterize their lives as chaotic. ${ }^{21}$

There is a general belief that continuity has to be experienced to be valued. One study found that longer registration with a practice led to being more likely to receive care from a personal general practitioner (GP). ${ }^{22}$ Continuity of care was more valued by those who had been with their physician longer ${ }^{20,23}$ or for more visits. ${ }^{20} \mathrm{~Pa}-$ tients' value for continuity increased when patients had a shared experience, described as "been through a lot together," with a physician, ${ }^{23}$ or when a serious life event had been experienced in the past 5 years. ${ }^{8}$ Length of time with one's physician and a strong belief in the importance of continuity were the strongest predictors of trust. $^{24}$ A qualitative study of patients who had been with their physicians longer than 15 years sheds further light on these findings. These patients identified a relationship that was developed over the years, and encompassed the passage of critical life events. They felt their providers showed time, interest, and a willingness to put extra effort into caring for them. ${ }^{25}$

\section{Value Measured by Willingness to Wait or Pay}

Patients may indicate the value that they place on interpersonal continuity of care by waiting longer to see their physician when ill or paying extra to see their physician. Numerous studies have found that people who value continuity state they are willing to wait to be seen by their regular physician. ${ }^{11,12,26-28}$ One study found that over half of those surveyed would be willing to pay a nominal monthly fee for their physician, and those with chronic conditions were more likely to say they would pay extra money for continuity. ${ }^{12}$

\section{For What Medical Situations Is Interpersonal Continuity of Care Valued? \\ Chronic Conditions}

Overall, continuity of care seems to be important to patients with chronic conditions. Multiple studies have found that patients with chronic conditions were more likely to want interpersonal continuity of care ${ }^{12,20,28}$ or that patients preferred continuity for chronic conditions ${ }^{29}$ or complex problems. ${ }^{21}$ Similarly, a worse self-reported health status was also associated with "a higher value placed on continuity." 20 Only one study from The Netherlands did not find a significant relationship between chronic illness and a greater desire for personal continuity. $^{8}$

Interpersonal continuity has been studied in patients with specific chronic conditions and found to be important to parents of children with cleft lip and palate, ${ }^{26}$ asthma, ${ }^{28}$ and to patients with rheumatic diseases. ${ }^{30}$ Other studies have found that the majority of patients state a preference for their regular doctor for potentially chronic conditions such as back pain, ${ }^{11,31}$ seasonal allergies, and depression. ${ }^{11}$ Patients with chronic illness were found to value regular visits with their physician to check the progression of their disease. ${ }^{32}$ Besides interpersonal continuity, chronic disease patients seem to value the transfer of their medical information between providers, which has been termed informational continuity. ${ }^{9}$ Chronic disease patients appreciate informational continuity in the situations involving transfer of care between nurse and physician, ${ }^{30}$ hospitalization, ${ }^{32}$ and outpatient care teams. $^{7}$ They report that this transfer of information saves them time by not having to repeat information. ${ }^{7,32}$

\section{Psychiatric Conditions}

Continuity of care has been examined in a few studies dealing exclusively with patients with mental illness. ${ }^{5,33,34}$ Themes from this literature about what is desired and valued are similar to those found in the general literature. In a study of lowincome patients with schizophrenia, ${ }^{33}$ patients appreciated the relationship with their practitioner, described in terms of "feeling known," "feeling like somebody," "looking for common ground," and "getting extra things." Communication was emphasized with the themes of "the importance of talk" and "input into treatment." Other important aspects of the relationship were access factors: "practitioner availability" and "practitioner flexibility." Similar to other patients with chronic diseases, patients with mental illness wanted informational continuity with new providers so that life histories did not have to be repeated. ${ }^{34}$

\section{Other Situations}

Other situations where a majority of patients preferred interpersonal continuity of care were in the discussion of personal ${ }^{8,27}$ or family problems, ${ }^{8,22}$ 
emotional concerns, ${ }^{21}$ the future when seriously ill, ${ }^{8}$ or during a serious life event. ${ }^{35}$ Patients also desired interpersonal continuity when presenting with symptoms such as sudden, severe breast pain, unexpected blood in stools, and abdominal pains. ${ }^{8}$ Various studies also have found interpersonal continuity to be valued across settings such as the emergency department ${ }^{11}$ or hospital. ${ }^{11,32,35}$

Patients seem to distinguish between more serious or psychological issues where interpersonal continuity is valued and other medical issues where other factors such as convenience take precedence. ${ }^{22}$ This has been investigated specifically for conditions such as sore throat, ${ }^{31}$ severe cough and cold, ${ }^{22}$ a painful problem, ${ }^{29}$ a visit resulting in lost work, ${ }^{29}$ and an acute injury-cut, sprain, ${ }^{8,29}$ or splinter in the eye. ${ }^{8}$

Continuity of care has been associated with increased receipt of preventive services. ${ }^{1}$ However, literature available about patients' preference for interpersonal continuity in preventive care is scarce. One study found that interpersonal continuity was preferred for yearly and required physical exams. ${ }^{29}$ Another study, however, found that only those parents who were in the top third of valuing continuity actually received a significant amount of interpersonal continuity for well child visits. ${ }^{36}$ Other studies have found that only $37 \%$ to $50 \%$ of patients thought seeing a personal doctor was important for regular blood pressure checks. ${ }^{8,22}$

\section{Why Is Interpersonal Continuity Valued?}

Several studies, particularly those using qualitative methodology, have examined why patients value a longitudinal continuity of care relationship with a health care provider. Themes across this literature are characteristics of the doctor patient relationship, knowledge of the patient, communication, and confidence/trust.

\section{Doctor-Patient Relationship}

The relationship with the doctor is one of the reasons why patients value having a usual physician. ${ }^{19,25}$ Patients who had been affiliated with practices at least 15 years characterized their physicians as "caring, personable, and dedicated," going beyond professional obligations, ${ }^{6,25}$ or overall just "liked" them. ${ }^{6}$ In one study, liking was described as "having an easy and comfortable relationship with the doctor." 37 Over time, patients enjoy feeling known ${ }^{17}$ and having a sense of famil- iarity with the physician. ${ }^{6}$ For some patients the relationship was characterized as a mutual bond, similar to friendship. ${ }^{6,17}$ In some ways, the continuity relationship is reciprocal. Recent results from a focus groups of diabetic patients suggest that patients recognized personal self-responsibility as an element of continuity-they were responsible for attending appointments and receiving information about their problems. ${ }^{7}$ A focus group of patients in Montreal felt that patients had a role in communicating with their doctors, and collaborating with them, as well as attending appointments and being receptive to recommendations. ${ }^{13}$

For some patients, having a usual physician is not important. A Swiss study that compared patients from an outpatient residency-type clinic with those from a private practice found that the interpersonal characteristics of the doctor-patient relationship were not as important to the outpatients as structural factors such as the clinic's investigational facilities. However, these patients also expected that their physicians be committed and good listeners. Many of them actually preferred discontinuity of care because it allowed for a second opinion and allowed them to interact with younger doctors that were seen as having more professional behavior. ${ }^{17}$ This idea of a second opinion from a different doctor has been found in other studies as well, with patients valuing that a different person brings a new perspective to their care. ${ }^{32,38}$

\section{Knowledge}

Patients value that their usual physician has an extended knowledge base about them, their families, and their past. A regular physician has knowledge of the patient's background: medical and personal histories, family relationships, and important life experiences. ${ }^{6,8,19,21}$ By usual physicians being "familiar with their circumstances," themselves as receiving "complete care" ${ }^{7}$ or better care of their medical condition. ${ }^{8}$

\section{Communication}

Patients also place importance on being able to communicate with their physician as part of a continuity relationship. ${ }^{6,25,32,40}$ This is often viewed as a partnership, with the doctor being both "willing to talk and listen." ${ }^{40}$ Patients related that their usual physicians were empathetic to their concerns. ${ }^{21}$ Over time, patients gained the confidence to "express their needs" to the physician. ${ }^{32}$ Patients 
want both to be understood by the physician when describing their problems, and to understand the physician as he or she explains their condition. 6,25 This information sharing requires "active participation by both parties,"7 and patients valued partnering with the physician to agree about a management plan. ${ }^{25}$

\section{Trust and Confidence}

The idea that trust and confidence in a physician develops over time is supported both by themes from qualitative studies ${ }^{6,21,32}$ and a cross sectional survey where length of time with a usual physician was associated independently with trust. ${ }^{24}$ Seeing a familiar GP has been related to higher levels of satisfaction and trust. ${ }^{41}$ A study of African American patients found that a stated barrier to developing a trusting relationship with a physician was having to change physicians frequently. ${ }^{42}$ A Swiss study found that trust was the number one reason patients remained with a particular practice. ${ }^{17}$ Trust develops based on the accumulation of caring experiences ${ }^{25}$ or familiarity with the physician's style and satisfaction with results. ${ }^{6}$ The developed trust and confidence leads to loyalty to a particular physician ${ }^{43}$ and the ability to accept lesser care at certain episodes if the usual care has been satisfactory. ${ }^{3}$

\section{Conclusions}

In the United States health care system, choice exists for many patients regarding priority of interpersonal continuity of care versus other factors such as access. Our review suggests that interpersonal continuity of care is not valued by all patients or across all settings. In particular, people seem to self-select to practices that fit their needs and prioritize interpersonal continuity less for certain conditions or situations. However, a review of existing studies also suggests that continuity of care seems to be important to most people, particularly vulnerable patients including parents of young children, the elderly, poor, less educated or those with chronic conditions. These vulnerable patients are less likely to have choice regarding the extent of continuity that they receive. Thus, as the health care system shifts from interpersonal continuity to site-based continuity, it becomes important to understand the perceived benefits of interpersonal continuity of care for those who desire it, and any difference in health outcomes that may result from the shift.

On the surface, the findings from our review that a majority of people prefer continuity may seem to contradict the results from the Future of Family Medicine (FFOM) Project that indicate widespread public disbelief in the existence of "a comprehensive care provider who treats a broad range of health care problems." ${ }^{44}$ However, the project also found that beyond basic access, communication and experience factors, patients value "the relationship with their physician above all else." Thus, the report suggests to the authors that the concept of continuity of care is not well understood by many patients, who may communicate about continuity using different language such as trust and partnership. In addition, much of the FFOM research was performed with a random probability sample of the public, which likely differs significantly from the respondents in the studies reviewed who all had experience as patients. As suggested by our review, patient's value for continuity may increase as they experience it.

To our knowledge, this is the first contextual review of the literature on patients' perceptions of interpersonal continuity of care. This review highlights that significant gaps exist in the interpersonal continuity of care literature regarding health outcomes from receipt of desired continuity, second opinions, and cost effectiveness. Future research should continue to explore when continuity is and is not important to patients. In particular, are there medical consequences when those who desire continuity do not receive it? Future research should also investigate what actual benefit patients perceive from having a doctor that has extended knowledge about them. In addition, the concept of desiring a second opinion from a different provider was mentioned in a few studies. Future research should investigate when discontinuity actually allows for beneficial new perspectives on care and the cost-effectiveness of such an approach. Answering these questions will provide insight into when interpersonal continuity is a worthwhile health intervention and its limitations.

The information presented in this review is important for practicing clinicians as they reflect on their practice style and office scheduling procedures. Clinicians can build patients' trust and confidence through demonstrating behaviors such as caring, listening, and acknowledging accumulated 
information. Clinicians should consider patients' preferences when creating office schedules by prioritizing continuity for patients with a strong continuity preference, chronic conditions, or emotional concerns. The potential benefit of a fresh perspective occurring from occasionally scheduling a willing patient to see a different provider from the same site should be considered. However, office schedules should also reflect the need for interpersonal continuity to be experienced to be valued by scheduling willing patients with the same provider when possible.

\section{References}

1. Saultz JW, Lochner J. Interpersonal continuity of care and care outcomes: a critical review. Ann Fam Med 2005;3:159-66.

2. Gill JM, Mainous AG, 3rd. The role of provider continuity in preventing hospitalizations. Arch Fam Med 1998;7:352-7.

3. Christakis DA, Wright JA, Koepsell TD, Emerson $\mathrm{S}$, Connell FA. Is greater continuity of care associated with less emergency department utilization? Pediatrics 1999;103:738-42.

4. Gill JM, Mainous AG, 3rd, Nsereko M. The effect of continuity of care on emergency department use. Arch Fam Med 2000;9:333-8.

5. Bjoerkman T, Hansson L, Svensson B, Berglund I. What is important in psychiatric outpatient care? Quality of care from the patient's perspective. Int J Qual Health Care 1995;7:355-62.

6. Gabel LL, Lucas JB, Westbury RC. Why do patients continue to see the same physician? Fam Pract Res J 1993;13:133-47.

7. Nair KM, Dolovich LR, Ciliska DK, Lee HN. The perception of continuity of care from the perspective of patients with diabetes. Fam Med 2005;37:118-24.

8. Schers H, Webster S, van den Hoogen H, Avery A, Grol R, van den Bosch W. Continuity of care in general practice: a survey of patients' views. Br J Gen Pract 2002;52:459-62.

9. Saultz JW. Defining and measuring interpersonal continuity of care. Ann Fam Med 2003;1:134-43.

10. Saultz JW, Albedaiwi W. Interpersonal continuity of care and patient satisfaction: a critical review. Ann Fam Med 2004;2:445-1.

11. Lewis CL, Wickstrom GC, Kolar MM, et al. Patient preferences for care by general internists and specialists in the ambulatory setting. J Gen Intern Med 2000;15:75-83.

12. Pereira AG, Pearson SD. Patient attitudes toward continuity of care. Arch Intern Med 2003;163:90912.

13. Roberge D, Beaulieu M, Haddad S, Lebeau R, Pie- neault R. Loyalty to the regular provider: patient' and physicans' views. Fam Pract 2001;18:53-9.

14. Baker R. Characteristics of practices, general practitioners, and patients related to levels of patients' satisfaction with consultations. Br J Gen Pract 1996; 46:601-5.

15. Roland M, Mayor V, Morris R. Factors associated with achieving continuity of care in general practice. J R Coll Gen Pract 1986;36:102-4.

16. Salisbury C, Manku-Scott T, Moore L, Chalder M, Sharp D. Questionnaire survey of users of NHS walk-in centres: observational study. Br J Gen Pract 2002;52:554.

17. Perron NJ, Favrat B, Vannotti M. Patients who attend a private practice vs a university outpatient clinic: how do they differ?. Swiss Med Wkly 2004; 134:730-7.

18. Flocke SA, Miller WL, Crabtree BF. Relationships between physician practice style, patient satisfaction, and attributes of primary care. J Fam Pract 2002;51: 835-40.

19. Brown JB, McWilliam CL, Mai V. Barriers and facilitators to seniors' independence. Perceptions of seniors, caregivers, and health care providers. Can Fam Physician 1997;43:469-75.

20. Nutting PA, Goodwin MA, Flocke SA, Zyzanski SJ, Stange KC. Continuity of primary care: to whom does it matter and when?. Ann Fam Med 2003;1: 149-55.

21. Tarrant C, Windridge K, Boulton M, Baker R, Freeman G. How important is personal care in general practice? BMJ 2003;326:1310.

22. Kearley KE, Freeman GK, Heath A. An exploration of the value of the personal doctor-patient relationship in general practice. Br J Gen Pract 2001;51: 712-8.

23. Mainous AG, 3rd, Goodwin MA, Stange KC. Patient-physician shared experiences and value patients place on continuity of care. Ann Fam Med 2004;2: 452-4.

24. Mainous AG, 3rd, Baker R, Love MM, Gray DP, Gill JM. Continuity of care and trust in one's physician: evidence from primary care in the United States and the United Kingdom. Fam Med 2001;33: 22-7.

25. Brown JB, Dickie I, Brown L, Biehn J. Long-term attendance at a family practice teaching unit. Qualitative study of patients' views. Can Fam Physician 1997;43:901-6.

26. Canady JW, Means ME, Wayne I, Thompson SA, Richman LC. Continuity of care: University of Iowa Cleft Lip/Palate Interdisciplinary Team. Cleft Palate Craniofac J 1997;34:443-6.

27. Freeman GK, Richards SC. Is personal continuity of care compatible with free choice of doctor? Patients' views on seeing the same doctor. Br J Gen Pract 1993;43:493-7.

28. Love MM, Mainous AG, 3rd. Commitment to a 
regular physician: how long will patients wait to see their own physician for acute illness? J Fam Pract 1999;48:202-7.

29. Kibbe DC, Bentz E, McLaughin CP. Continuous quality improvement for continuity of care. J Clin Nurs 1996;36:304.

30. Temmink D, Hutten JB, Francke AL, Abu-Saad $\mathrm{HH}$, van der Zee J. Quality and continuity of care in Dutch nurse clinics for people with rheumatic diseases. Int J Qual Health Care 2000;12:89-95.

31. Stoddart H, Evans M, Peters TJ, Salisbury C. The provision of 'same-day' care in general practice: an observational study. Fam Pract 2003;20:41-7.

32. Infante FA, Proudfoot JG, Powell Davies G, et al. How people with chronic illnesses view their care in general practice: a qualitative study. Med J Aust 2004;181:70-3.

33. Ware NC, Tugenberg T, Dickey B. Practitioner Relationships and quality of care of low-income persons with serious mental illness. Psychiatric Services May 2004;55:555-9.

34. Ware NC, Tugenberg T, Dickey B, McHorney CA. An ethnographic study of the meaning of continuity of care in mental health services. Psychiatr Serv 1999;50:395-400.

35. Schers H, van de Ven C, van den Hoogen H, Grol R, van den Bosch W. Patients' needs for contact with their GP at the time of hospital admission and other life events: a quantitative and qualitative exploration. Ann Fam Med 2004;2:462-8.

36. Christakis DA, Kazak AE, Wright JA, Zimmerman FJ, Bassett AL, Connell FA. What factors are asso- ciated with achieving high continuity of care? Fam Med 2004;36:55-60.

37. Lings P, Evans P, Seamark D, et al. The doctorpatient relationship in US primary care. J R Soc Med 2003;96:180-4.

38. Liaw ST, Litt J, Radford A. Patient perceptions of continuity of care: is there a socioeconomic factor? Fam Pract 1992;9:9-14.

39. Pooley CG, Gerrard C, Hollis S, Morton S, Astbury J. 'Oh it's a wonderful practice. . you can talk to them': a qualitative study of patients' and health professionals' views on the management of type 2 diabetes. Health Soc Care Community 2001;9:318 26.

40. O'Malley AS, Forrest CB, O'Malley PG. Low-income women's priorities for primary care: a qualitative study. J Fam Pract 2000;49:141-6.

41. Schers H, van den Hoogen H, Bor H, Grol R, van den Bosch W. Familiarity with a GP and patients' evaluations of care. A cross-sectional study. Fam Pract 2005;22:15-9.

42. Torke AM, Corbie-Smith GM, Branch WT, Jr. African American patients' perspectives on medical decision making. Arch Intern Med 2004;164:525-30.

43. Schers H, Webster S, van den Hoogen H, Avery A, Grol R, van den Bosch W. Continuity of care in general practice: a survey of patients' views. Br J Gen Pract 2002;52:459.

44. Martin JC, Avant RF, Bowman MA, et al. The Future of Family Medicine: a collaborative project of the family medicine community. Ann Fam Med 2004;2 Suppl 1:S3-32. 